\title{
Proposal of a Tall Man Letter list for German-speaking countries
}

\author{
Johannes Heck $^{1}$ (D) $\cdot$ Adrian Groh $^{2}$ (D) $\cdot$ Dirk O. Stichtenoth ${ }^{1,3}$ (D) Olaf Krause $^{4}$
}

Received: 9 November 2020 / Accepted: 13 January 2021 / Published online: 27 January 2021

(C) The Author(s) 2021

Medication errors represent an avoidable threat to patient safety [1] and include - but are not limited to - administration of a drug to the wrong patient, choice of an incorrect route of administration, and administration of the false drug [2]. Administration of the false drug may result from the confusion of two similarly looking and/or sounding drug names, the socalled look-alike/sound-alike (LASA) medications [3]. We have previously reported on three cases of insidious LASA medication errors that occurred at our university hospital [4].

Since Hannover Medical School is obliged to a policy of transparent error management, the published cases [4] have been thoroughly investigated and potential countermeasures have been discussed to avoid similar scenarios in the future. Tall Man Lettering (TML) describes a concept of partial capitalisation of drug names that aims at better distinguishability, thereby reducing the risk of confusion of LASA medications [3, 5]. Internationally, several TML lists in English exist. In the USA, the Food and Drug Administration (FDA) has published a list with TML notations in 2001 as part of the agency's name differentiation project [6]. The original FDA TML list has been amended by the Institute for Safe Medication Practices (ISMP) since 2008 [6]. ISMP Canada, in cooperation with the Canadian Association of Provincial Cancer Agencies, has published a similar TML list [7], yet with a focus on antineoplastic agents. An example for a TML list in a local language (i.e. Spanish) is the list by Otero López and colleagues [8].

Johannes Heck

heck.johannes@mh-hannover.de

1 Institute for Clinical Pharmacology, Hannover Medical School, Carl-Neuberg-Str. 1, 30625 Hannover, Germany

2 Department for Psychiatry, Social Psychiatry and Psychotherapy, Hannover Medical School, Hannover, Germany

3 Drug Commissioner, Hannover Medical School, Hannover, Germany

4 Institute for General Medicine, Hannover Medical School, Hannover, Germany
In the aftermath of the disturbing cases of LASA medication errors that occurred at our institution [4], an interdisciplinary expert panel comprised of representatives from clinical pharmacology, psychiatry, and general medicine convened and decided to create a TML list in German. To this end, existing TML lists [6-8] were screened and appropriate agents were selected based on their availability and frequency of use in Germany. Medications predominantly prescribed by specialists, e.g. antineoplastic agents, were largely avoided in favour of more commonly used drugs such as antihypertensives, anti-infectives, and psychopharmaceuticals. For drugs used in emergency and intensive care medicine, TML recommendations in German already exist [9] and have been implemented at our university hospital. Of note, the drugs that had been confused in ref. [4] were incorporated into our list.

The final list which features TML notations in German for 44 LASA drug pairs/groups, comprising a total of 101 individual agents, was presented to, and approved by the Drug Commission of Hannover Medical School (Table 1 and Supplement 1). The list will be distributed to all newly employed physicians at our institution, accompanied by a brief description of the concept of TML. The primary goal of the list is the sensitisation of physicians to the problem of LASA medication errors. The list is a recommendation from physicians for physicians, its use is not mandatory. Physicians are encouraged to take advantage of TML in situations which bear a high risk of confusion of LASA drug names or if a problem with recurring confusion of certain LASA medications has been identified. Routine use of TML notations for every prescription, on the other hand, would be too time-consuming and is therefore not recommended. Even though the list has primarily been developed for handwritten prescriptions, it can also be incorporated into electronic prescription systems.

The presented TML list (Table 1) may be used beyond our own institution in other countries where German is (one of) the official language(s), i.e. Austria, Belgium, Liechtenstein, Luxembourg, and Switzerland, as well as in countries with a language partly similar to German, e.g. the Netherlands and Scandinavian countries. Local adaptations regarding drug 
Table 1 Tall Man Letter list of Hannover Medical School, Hannover, Germany. The original German version is available as Supplement 1. Please note that drug names in German, as all nouns, start with a capital letter. TML, Tall Man Letter

\begin{tabular}{|c|c|c|c|}
\hline \multicolumn{2}{|c|}{ Drug pair/drug group in German TML notation } & \multirow{2}{*}{\multicolumn{2}{|c|}{$\begin{array}{l}\text { Drug pair/drug group in German TML notation } \\
\text { LevETIRAcetam - LevOCARNitin - LevoFLOXacin }\end{array}$}} \\
\hline AMILorid & AmLODIPin & & \\
\hline ARICept® (Donepezil) & AZILect ${ }^{\circledR}$ (Rasagilin) & LEVOmethadon & Methadon \\
\hline AzaCITIDin & AzaTHIOprin & LORAtadin & LoVAStatin \\
\hline BuPROPion & BuSPIRon & MELperon & MeroNEM® bzw. MeroPENEM \\
\hline \multicolumn{2}{|c|}{$\begin{array}{l}\text { CefAZOLin - CefOTAXim - CefTAZIdim }- \text { CefTRIAXon - } \\
\text { CefUROXim }\end{array}$} & MONurol® (Fosfomycin) & MOVIcol® (Macrogol 3350) \\
\hline CITalopram & EScitalopram & NalTREXon & NaPROXen \\
\hline \multicolumn{2}{|c|}{ CloBAZam - CloNIDin - CloPIDOgrel - CloZAPin } & NexAVAR® (Sorafenib) & NexIUM® (Esomeprazol) \\
\hline \multicolumn{2}{|c|}{ CLOTrimazol — CloMETHiazol — CoTRIMoxazol } & PAZOPanib & PONATinib \\
\hline ClomiFEN & ClomiPRAMIN & PenicillAMIN & Penicillin \\
\hline CycloSERIN & CycloSPORIN & PENTobarbital & PHENobarbital \\
\hline DACTINomycin & DAPTOmycin & PirACEtam & PirOXIcam \\
\hline \multicolumn{2}{|c|}{ DiazePAM — DilaTREND® (Carvedilol) — DilTIAZem } & PireTANid & PiriTRAMid \\
\hline DimenhyDRINAT & DiphenhydrAMIN & PrednisoLON & PredniSON \\
\hline DipiDOLOR® (Piritramid) & DipiPERON® (Pipamperon) & RifAMPicin & RifAXIMin \\
\hline EbiXA® (Memantin) & EviSTA® (Raloxifen) & \multicolumn{2}{|c|}{$\begin{array}{l}\text { RisperDAL }{ }^{\circledR} \text { bzw. RisperiDON }- \text { RoHYPnol }{ }^{(} \text {(Flunitrazepam) - } \\
\text { ROPInirol }\end{array}$} \\
\hline EdoXABAN & ENDOxan ${ }^{\circledR}$ (Cyclophosphamid) & SandIMMUN® (Ciclosporin) & SandoSTATIN® (Octreotid) \\
\hline EpiRUBIcin & EriBULin & SulfaDIAzin & SulfaSALAzin \\
\hline FluCLOXAcillin & FluconAZOL & TerBINafin & TerFENAdin \\
\hline FOSamax® (Alendronsäure) & TOPamax® (Topiramat) & TiaNEPtin & TiZANidin \\
\hline \multicolumn{2}{|c|}{$\begin{array}{l}\text { HydrALAZIN - HydroCHLOROthiazid - HydroCORTison - } \\
\text { HydroMORPHon - HydrOXYzin }\end{array}$} & TraMADol & TraZODon \\
\hline IDArubicin & IdaruCIZUmab & ValACIclovir & ValGANciclovir \\
\hline \multicolumn{2}{|c|}{ 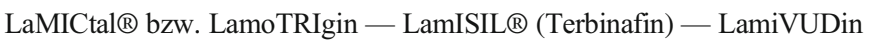 } & ZyPREXA® (Olanzapin) & ZyrTEC® (Cetirizin) \\
\hline
\end{tabular}

availability and frequency of use may be necessary. We strongly encourage colleagues in non-German-speaking countries to develop TML lists in the respective local language since TML is an acknowledged strategy to avoid LASA medication errors $[3,5]$.

Supplementary Information The online version contains supplementary material available at https://doi.org/10.1007/s00228-021-03091-3.

Acknowledgments The authors would like to thank all members of the Drug Commission of Hannover Medical School for supporting the project of a German Tall Man Letter list.

Authors' contributions The first draft of the manuscript was written by Johannes Heck, Adrian Groh, and Olaf Krause. Dirk O. Stichtenoth commented on previous versions of the manuscript. All authors read and approved the final manuscript. This work was supervised by Dirk O. Stichtenoth.

Funding Open Access funding enabled and organized by Projekt DEAL.

\section{Compliance with ethical standards}

Conflict of interest The authors declare no conflict of interest.
Open Access This article is licensed under a Creative Commons Attribution 4.0 International License, which permits use, sharing, adaptation, distribution and reproduction in any medium or format, as long as you give appropriate credit to the original author(s) and the source, provide a link to the Creative Commons licence, and indicate if changes were made. The images or other third party material in this article are included in the article's Creative Commons licence, unless indicated otherwise in a credit line to the material. If material is not included in the article's Creative Commons licence and your intended use is not permitted by statutory regulation or exceeds the permitted use, you will need to obtain permission directly from the copyright holder. To view a copy of this licence, visit http://creativecommons.org/licenses/by/4.0/.

\section{References}

1. Payne R, Franklin BD, Slight S, Avery A (2016) Medication errors: technical series on safer primary care. World Health Organization, Geneva

2. Tariq RA, Vashisht R, Scherbak Y (2020) Medication errors. StatPearls Treasure Island (FL): StatPearls Publishing LLC 
3. Bryan R, Aronson JK, Williams A, Jordan S (2020) The problem of look-alike, sound-alike name errors: drivers and solutions. Br J Clin Pharmacol. https://doi.org/10.1111/bcp.14285

4. Heck J, Groh A, Stichtenoth DO, Bleich S, Krause O (2020) Lookalikes, sound-alikes: three cases of insidious medication errors. Clin Case Rep. 8:3284-3287. https://doi.org/10.1002/ccr3.3409

5. Larmené-Beld KHM, Alting EK, Taxis K (2018) A systematic literature review on strategies to avoid look-alike errors of labels. Eur J Clin Pharmacol 74:985-993

6. Institute for Safe Medication Practices. FDA and ISMP lists of lookalike drug names with recommended tall man letters. https://www. ismp.org/sites/default/files/attachments/2017-11/tallmanletters.pdf. Accessed 09 Nov 2020

7. Institute for Safe Medication Practices Canada. TALLman lettering for look-alike/sound-alike drug names in Canada. https:/www.ismpcanada.org/download/TALLman/TALLman_lettering.pdf. Accessed 09 Nov 2020
8. Otero López MJ, Martin Munoz R, Sanchez Barba M, Abad Sazatornil R, Andreu Crespo A, Arteta Jimenez M et al (2011) Development of a list of look-alike drug names with recommended tall man letters. Farm Hosp 35:225-235

9. Deutsche Interdisziplinäre Vereinigung für Intensiv- und Notfallmedizin (DIVI). Empfehlung zur Kennzeichnung von Spritzen in der Intensiv- und Notfallmedizin 2012 - erste Überarbeitung des „DIVI-Standards“. https://www.divi.de/ joomlatools-files/docman-files/publikationen/empfehlungspritzenetiketten/20120702-publikationen-divi-spritzenetikettenempfehlung.pdf. Accessed 09 Nov 2020

Publisher's note Springer Nature remains neutral with regard to jurisdictional claims in published maps and institutional affiliations. 